\title{
A Case Report on a Very Rare Condition: Prenatal Diagnosis of Diastematomyelia and its Clinical Significance
}

\author{
Pervin Karlı* \\ Department of Obstetrics and Gynecology, Amasya University Research Hospital, Turkey
}

Submission: August 08, 2018; Published: August 22, 2018

*Corresponding author: Pervin Karl, Associate Prof, Department of Obstetrics and Gynecology, Amasya University Research Hospital, 05000 Amasya, Turkey, Tel: +903582184000/ 1805; Fax: +903582120001; Email: parpi2300@hotmail.com/pervin.karli@amasya.edu.tr

\begin{abstract}
Objective: Diastematomyelia (DMM), also called split cord malformation, is a developmental embryologic midline anomaly and is characterized by formation of 2 spinal cords. It is classified in 2 groups, Type 1 and 2. Formation of a scoliosis is a major factor in its etiology. In the process of assessing a patient with DMM, cooperation between a brain surgeon and an orthopedist as well as prenatal diagnosis are important for presenting early diagnosis, treatment and follow-up options. İn this report we presented the case of DMM which was diagnosed as a rare prenatal.

Case report: An echogenic focus in the lower lumbal region of the spinal cord and dilation in the spinal cord in that area were seen in the prenatal scanning at Week 16 of the 31-year-old patient who had no known comorbidities. As a result of further examinations and imaging methods used, she was diagnosed with DMM and referred to an advanced facility. The patient was informed through an interview with the brain surgeon about the long-term sequelae and outcomes of this condition, and its treatment options, an informed consent was obtained from her and she was offered a choice between continuing with the pregnancy and stopping it. Her pregnancy was terminated of her own will and insistence as her socioeconomic status did not allow continuation of it.

Conclusion: DMM is a condition that can survive, but paraplegia may occur despite proper treatment in later ages. Prenatal diagnosis is important in offer a choice for options such as early diagnosis , treatment and termination of pregnancy if there are with other anomalies.

Keywords: Diastematomyelia; Prenatal diagnosis; Split cord malformation

Abbreviations: DMM: Diastematomyelia; CT: Computerized Tomography; AFP: Alpha Fetoprotein; NTDs: Neural Tube Defects; JLS: Jarcho-Levin Syndrome; SCM: split cord malformation
\end{abstract}

\section{Introduction}

Split cord malformation (SCM), also called diastematomyelia (DMM), is a rare form of short stature associated with the spinal cord, which is characterized by a split in the spinal cord and is considered as a neuro-orthopedic syndrome [1,2]. It is often seen in lower thoracic and lumbar regions. It has two types, 90\% being Type 1 DMM. In Type 1, there are two split spinal cords both in their own dural sacs. Since there are not duplicated innervations coming from both of the split spinal cords, it will not actually be quite correct to use the term dual spinal cord [3]. Type 2 SCM involves formation of two half-sized spinal cords that are separated by a fibrous septum in midline in a common dural sac. In this condition called "diplomyelia", there are two separate spinal cords both having their own motor and sensory innervations $[2,4]$. Both types of DMM can be seen in the same patient at various levels. Sometimes, partial DMM can be found in patients. DMM may be isolated or accompanied by skeletal anomalies (e.g. rib abnormalities, butterfly vertebrae, spina bifida, hemivertabrae), fibrous spurs, dermoid tumors, meningocele or meningomyelocele, thick filum terminale, filum terminale lipoma, hydromyelia, myelophthisis, intradural lipoma, dermoid cyst, or skin conditions (e.g. hypertrichosis, capillary hemangioma, dermal sinus tracts and subcutaneous lipoma) $[3,5]$.

Their embryogenesis processes are thought to be similar. It starts producing clinical symptoms between ages 4 and 6.5 and is seen 3 times more in females [2,4]. Cases with familial transmission have also been reported although their transmission routes are not clear [2]. Skin symptoms (focal hirsutism at midline, hemangioma, dermal sinus tract, lipoma) and orthopedic deformities are seen at a rate of $71 \%$ in asymptomatic patients [2,4]. Bone deformities are common; anomalies such as scoliosis, hemivertabrae, butterfly vertebrae, block vertebrae and narrowed disc spaces are seen in $85 \%$ of the cases. Scoliosis occurs mostly as a result of straining of the spinal cord in these patients $[2,6]$. The limb lengths may be uneven in the lower extremities or there may be asymmetrical feet, muscular atrophies, lack of lower extremity reflexes, sensory defects in the feet and resulting atrophic lesions, cavovarus foot 
deformities, or hammer toes. Neurologically, motor dysfunction, loss of sensation or pain may occur. Chronic and recurrent lower back pain is present in $30 \%$ of children and in all adults $[2,6,7]$. Muscular weakness is mild but progressive. Sometimes, it can also present itself with an acute clinical condition after a trauma that strains the spinal cord [2]. Neurogenic bladder is more common in adults. The existing neurological deficits do not heal after a surgery [6]. The major radiological diagnosis methods are magnetic resonance imaging (MRI) and computerized tomography (CT) [4]. Use of ultrasound is more important in prenatal diagnosis and the condition manifests itself as an echogenic locus $[2,6]$. It is a condition that should be recognized in the intrauterine period. If scoliosis is present, first its cause should be identified because when scoliosis is corrected tense spinal cord syndrome and paraplegia may develop due to such tension. There is no consensus on its treatment. Early surgery is recommended for pediatric patients $[2,4,8]$. If surgery is intended, chronic progressive neurological deficit and scoliosis must be corrected for certain. Annual follow-up is appropriate in conservative approach. The common opinion is that if progression is predicted, early surgery is a fair choice $[2,4]$. Surgical outcomes are usually satisfactory although the amount of remission depends on the severity of the deficit.

\section{Case Report}

The 31-year-old patient did not have any known comorbidities including gestational diabetes, any known factor she was constantly exposed to, or any drug intake. There was no sign of high risk in her 2nd and 3rd trimester scans and alpha fetoprotein (AFP) was normal. During her routine examination with ultrasound at her gestational week 16, presence of a neural tube defect close to the sacrococcygeal region was suspected and close monitoring was recommended. The visual sign was not clear enough to fully correspond to neural tube defects (NTDs). Following the fetal MRI scan of the patient, she was diagnosed with diastematomyelia (DMM). The patient was informed about the long-term complications and prognosis of DMM. However, the patient requested termination of her pregnancy by way of medical abortion due to her socioeconomic status. In the image of the fetus after abortion, the skin at the fetal sacrococcygeal region had a lighter tone and there was a pouch resembling meningocele at that region. Further examination revealed no other anomalies (Figure 1-4).

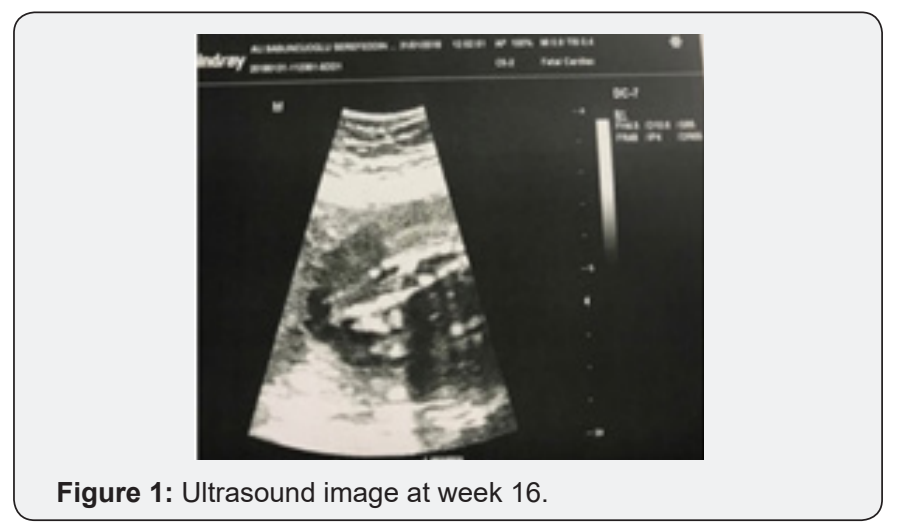

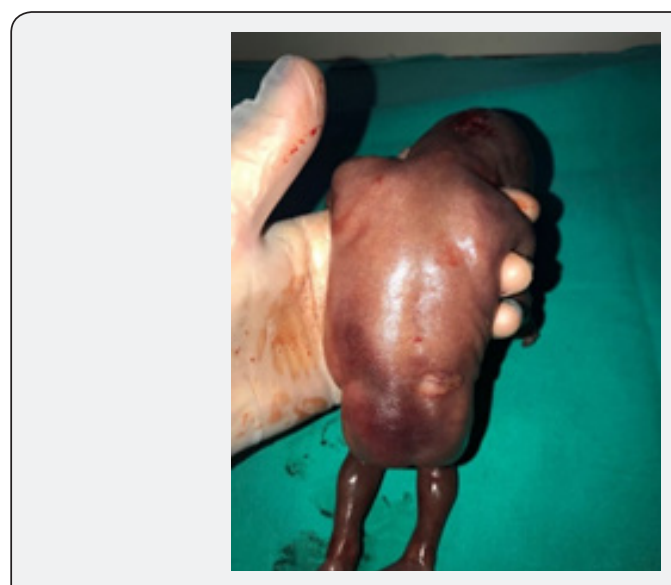

Figure 2: Image of the fetus after medical abortion.
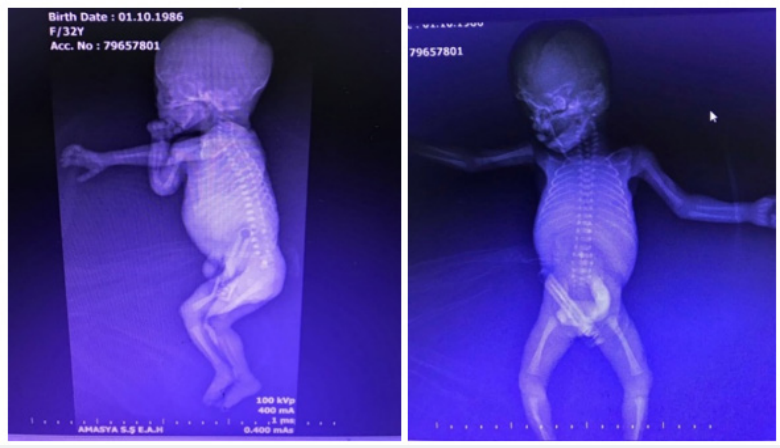

Figure 3 \& 4: Lateral and anterior radiological images of spinal cord.

\section{Discussion}

DMM is a clinical entity that can be detected in the first trimester of pregnancy through a careful spinal cord examination. DMM starts showing clinical symptoms with advancing age and may lead to a paraplegic condition impairing quality of life in the patient if not treated with surgical intervention and sometimes despite a surgical intervention. DMM can be detected in the prenatal period and there are cases in the literature reporting DMM both in the prenatal period and at advanced ages. Yüksel et al. [9] have presented a case report involving an 11-yearold girl, the daughter of a 38-year-old mother and a 52-yearold father, who had a combination of polymastia and DMM [9]. Subramanyam et al. [10] have reported a case as a component of the Jarcho-Levin syndrome (JLS). JLS is a rare and distinctive form of short trunk dwarfism with rib and vertebral anomalies. This is the first reported case of a newborn exhibiting an unusual combination of spondylothoracic and spondylocostal JLS with lung anomaly and diastematomyelia [10]. Aliye et al. [11] have reported two patients aged 41 and 52 years both presented with weakness and chronic pain in their legs [11]. Another case diagnosed at gestational week 20 was reported in 2006 . The pregnancy was monitored, and delivery was realized at gestational week 41 and no additional anomaly was found. The patient was referred to brain surgery [12]. In 2000, Allen et al. reported two cases involving Type 1 DMM with no accompanying anomalies or chromosomal disorders [13]. In their retrospective 
analysis of 27,085 cases, Has et al. [14] have reported 8 cases $(0.30 \%)$, all of which were identified at gestational weeks 20 and 21. Levels of $\alpha$-fetoprotein (AF-AFP) and acetylcholinesterase (AF-AChE) were examined and found high only in one patient. They also found accompanying myelomeningocele in that patient. Spontaneous miscarriage occurred 1 week later in one of the other seven patients and the pregnancies of the remaining six patients completed their terms resulting in births with no additional anomalies, except for one who had a single umbilical artery as an additional ultrasound finding. The results of longterm follow-ups of these patients are unknown; thus, whether or not they had any neurological sequelae is also unknown. In their literature search, Has et al. [14] found 26 DMM cases in 14 case reports and there were no biochemical or chromosomal abnormalities in 12 of them. In conclusion; prenatal diagnosis is also very important to offer treatment options.

\section{Conflicts of Interest}

Non-financial conflicts include personal or professional re-lationships, affiliations, academic competition, intellectual passion,knowledge or beliefs that might affect objectivity.

\section{References}

1. Benli IT, Un A, Karaaslan S, Cinemre O, Gürses L, et al. (2002) Neural axis abnormalities detected by preoperative magnetic resonance imaging in patients with type III idiopathic scoliosis. Acta Orthop Traumatol Turc 36(4): 354-361.

2. Sabuncuoğlu HT, Coşar AT (2008) Split kord malformasyonu: Diastometamyeli. Journal of Turkish Spinal Surgery 19(1): 47.

3. Pang D, Dias MS, Ahab-Barmada M (1992) Split cord malformation: Part I: A unified theory of embryogenesis for double spinal cord malformations. Neurosurgery 31(3): 451-480.

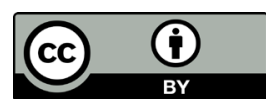

This work is licensed under Creative Commons Attribution 4.0 License DOI: 10.19080/JOJCS.2018.08.555734
4. Warf BJ (2004) Tethered spinal cord. Youmans neurological surgery. Saunders Company, Philadelphia, USA, pp. 3257-3287.

5. Arısoy Ö, Yılmaz E, Korucuoælu Ü, Biri A, Tarafl MB (2006) 20 haftalık bir fetusta Diastometamyelinin prenatal tanısı. TJOD Uzmanlık Sonrası Eğitim ve Güncel Gelişmeler Dergisi 3(2): 122-124.

6. Kaminker R, Fabry J, Midha R, Finkelstein JA (2000) A Split cord malformation with diastematomyelia presenting as neurogenic claudication in an adult: a case report. Spine (Phila Pa 1976) 25(17): 2269-2271.

7. Karadağ Ö, Aslan A, Gürelik M, Göksel HM (2002) Ayrık Omurilik Malformasyonu: iki Olgu Sunumu. C. Ü. Tıp Fakültesi Dergisi. Türk Omurga Cerrahisi Dergisi 24(3):153-157.

8. Dias MS, Pang D (1995) Split cord malformations. Neurosurg Clin N Am 6(2): 339-358.

9. Yuksel S, Coban YK (2011) Polymastia with diastometamyelia: case report. J Inonu Univ Med Faculty 18(1): 47-49.

10. Padma S, Sundaram PS (2015) Jarcho-Levin syndrome with association of unilateral pulmonary hypoplasia and diastometamyelia: A case illustration. Lung India 32(4): 416-418.

11. Temiztürk F, Güzelant AY, Temiztürk S, Özgüzel MH (2010) Split Kord Malformasyonu: İki Olgu Sunumu. Turkish Journal of Physical Medicine \& Rehabilitation/Turkiye Fiziksel Tip ve Rehabilitasyon Dergisi 56(1).

12. Arısoy Ö,Yılmaz E, Korucuoğlu Ü, Biri A, Mehmet Bülent Tıraş (2006) Prenatal Diagnosis of Diastematomyelia at 20th Gestational Week 2(3):122-124.

13. Allen LM, Silverman RK (2000) Prenatal ultrasound evaluation of fetal diastematomyelia: two cases of type I split cord malformation. Ultrasound Obstet Gynecol 15(1): 78-82.

14. Has R, Yuksel A, Buyukkurt S, Kalelioglu I, Tatli B (2007) Prenatal diagnosis of diastematomyelia: presentation of eight cases and review of the literature. Ultrasound Obstet Gynecol 30(6): 845-849.

\section{Your next submission with Juniper Publishers will reach you the below assets}

- Quality Editorial service

- Swift Peer Review

- Reprints availability

- E-prints Service

- Manuscript Podcast for convenient understanding

- Global attainment for your research

- Manuscript accessibility in different formats

( Pdf, E-pub, Full Text, Audio)

- Unceasing customer service

Track the below URL for one-step submission https://juniperpublishers.com/online-submission.php 